\title{
GESTÃO EM SEGURANÇA PÚBLICA: análise de competências gerenciais nos cargos de gestão em Segurança Pública
}

\author{
Deyvison Brito Monteiro ${ }^{7}$ \\ Thittps://orcid.org/0000-0002-9193-4604 Prof. Dr. Marcelo Pessoa ${ }^{8}$
}

DOI NUMBER: 10.33726/akedia2447-7656v1a12015p22-38

RESUMO: Sabemos que Segurança Pública é uma política bastante debatida no cenário da Governança Estatal, seja em nosso país ou em outros locais do mundo. Nesse viés, a aplicação de políticas públicas de segurança, permeia-se sobre a prestação de serviços sempre com um grau elevado de eficiência. Assim, a prática de segurança pública requer competências técnicas e comportamentais específicas de seus profissionais, principalmente para os tomadores de decisões ou gestores. A capacitação e treinamento dos gestores públicos, ora encarregados pela implementação, coordenação e controle dessas políticas, que em tese deixam a sociedade mais segura, sem sombra de dúvida, não deixa de ser uma excelente estratégia para o alcance de um ambiente cada vez mais seguro em nossa sociedade. Desse modo, acreditamos que essa pesquisa teve, com fim à realização de análise sobre quais são as competências gerenciais primordiais na seara da administração da Segurança Pública. Para tanto, afastou-se do campo das atuações genéricas, das boas doutrinas administrativas gerenciais, procurando sempre competências profissionais mais especificas, devido ao garbo que essa seara possui. Nesse trabalho, foi utilizado o método hipotético-dedutivo, pois a partir das teorias de base, documentos hodiernos dos órgãos de segurança pública e bibliografia existente, foi possível traçar um perfil profissiográfico. No almejo de tentar desvendar as principais competências gerencias dos profissionais de segurança pública, buscou-se nas fontes abertas, as competências gerencias desejadas dos gestores de segurança pública, configurando-se assim mais um instrumento de contribuição e reflexão para a elaboração de políticas públicas voltadas para a promoção de uma atuação cada vez mais qualificada. Diante de tal perspectiva, esse trabalho visa ainda contribuir para o mapeamento de competências gerenciais dos gestores de atividades de segurança pública, de modo a traçar um perfil que conduza ao caminho da Excelência Profissional por parte desses profissionais. Pretende-se com esse estudo, contribuir não apenas para o desenvolvimento e sustentabilidade das organizações públicas de segurança, mas, sobretudo, a promoção de mudanças de comportamento que demonstrem maior eficiência, eficácia e efetividade dos serviços prestados ao cidadão.

PALAVRAS-CHAVES: Competência, Gestão, Gestores e Segurança Pública.

ABSTRACT: We know that Public Safety is a policy widely discussed in the scenario of the State Governance, either in our country or elsewhere in the world. In this bias, the implementation of public security policies, permeates on

\footnotetext{
${ }^{7}$ Especialista em Gestão Pública pela FaPP - Faculdade de Políticas Públicas "Tancredo Neves", Unidade da UEMG - Universidade do Estado de Minas Gerais, Belo Horizonte.

${ }^{8}$ Orientador do Programa de Pós-Graduação da FaPP. Docente na UEMG, Unidade Frutal. Possui Bolsa de Professor Orientador - BPO. Desenvolve Projeto de Pesquisa com o apoio da UEMG e do Estado de Minas Gerais, via prêmio de fomento à pesquisa docente obtido por meio do Edital PAPq 08/2015.
}

AKEDIA - VERSÕES, NEGLIGENCIAS E OUTROS MUNDOS V.1 DEZ. DE 2015 - ISSN 2447-7656 
the service always with a high degree of efficiency. Thus, the public security practice requires specific technical and behavioral skills of its professionals, especially for decision-makers or managers. Capacity building and training of public officials, now responsible for the implementation, coordination and control of these policies, which in theory leave the safer society, without a doubt, it is still an excellent strategy for achieving an increasingly safe environment in our society. Thus, we believe that this research was, with order to carry out analysis of what are the primary managerial skills in harvest management of Public Security. Therefore, departed from the field of generic actions, good managerial administrative doctrines, always looking for more specific professional skills, due to elegant that this harvest has. In this work, we used the hypothetical-deductive method, as from the base of theories, modernday documents of the public security organs and existing literature, it was possible to trace a professional profile. In crave to try to unravel the main managerial skills of public safety professionals, we sought in open sources, the desired managerial skills of public safety managers, and has thus another tool and reflection contribution to the development of public policies to promote an increasingly qualified action. At this perspective, this work aims to contribute to the mapping of managerial skills of managers of public security activities in order to draw a profile that leads to the path of Professional Excellence by these professionals. The aim of this study contribute not only to the development and sustainability of public security organizations, but, above all, the promotion of behavior change that demonstrates the efficiency, efficacy and effectiveness of services provided to citizens.

KEY WORDS: Skill, Management, Managers and Public Safety.

\section{COMPETÊNCIAS GERÊNCIAS DE SEGURANÇA PÚBLICA}

A demanda social por qualidade nos serviços prestados ao cidadão tem crescido bastante. Fenômenos de comunicação de massa, visíveis por meio das redes sociais que funcionam pela internet, pela onipresença da imprensa televisiva, pela pulverização do acesso a recursos tecnológicos, ou também a partir de equipamentos como tablets, aparelhos celulares e congêneres, têm dado ao cidadão maior capacidade de vigilância e de cobrança junto aos gestores da coisa pública.

Isso, de um lado, é elemento positivo, na medida em que impõe aos interlocutores uma dinâmica de interação supostamente mais democrática, contudo, por outro lado, também acentua ainda mais, devido ao quesito transparência dos atos públicos, o teor de gravidade que se atribui aos deslizes praticados na gestão dos itens elementares das relações do Estado com o contribuinte. 
A Segurança Pública é um dentre os setores sensíveis desta relação, o qual se alinha direta ou indiretamente com as questões da Saúde Pública, da Educação, dos Transportes etc. Desse modo, buscando compreender o eixo norteador destas relações, julgamos válido recorrer ao pensamento sintético Cordeiro (2010), quando este nos diz que "Os investimentos em ações que promovam o conhecimento crítico, capacidades e competências para atividade profissional, é um fator primordial para o alcance dos objetivos das organizações públicas e privadas".

O constante desejo por soluções mais eficientes e céleres tem impulsionado a iniciativa pública a investir na qualidade. Igualmente, na busca contínua pela excelência, é possível vislumbrar a necessidade de se atender e superar as expectativas do "cliente - o cidadão" faz do planejamento estratégico governamental uma excelente estratégia que direciona as ações gerenciais com maior racionalidade, transparência e accountability ${ }^{9}$ (MINAS, 2014).

Como já se é sabido, o maior capital de qualquer instituição, são as pessoas. "Sem elas não se gera produtos nem serviços, não se constroem valores nem se fortalecem culturas" (BRASIL, 2012). De igual forma, mas não tão semelhante, o serviço de Segurança Pública, também tem como foco principal as relações humanas em sociedade. Contudo, devido à natureza restritiva de alguns direitos dos cidadãos por parte do Estado, o perfil desses profissionais deve ser pautado pela oferta de um perfil diferenciado, justamente por lidar com circunstâncias que exigem medidas extremas de cerceamento de liberdades e direitos (BRASIL, 2012).

Nesse mister, é importante salientar que, para os cargos públicos no setor da segurança, mais especificamente os gerenciais, pela alta gama de responsabilidade com o público e com os servidores públicos que realizam esse serviço, faz-se necessário um mapeamento específico do perfil profissional.

Desse modo, o trabalho em tela, pretende elencar de forma rasteira, nem por isso simplória, a feitura de uma análise de um padrão de perfil profissional para os gestores de Segurança Pública, já que esses profissionais

\footnotetext{
${ }^{9}$ Accountability - remete para dimensões como prestação de contas, responsabilidade social,
} verificação da qualidade de serviço prestado, escrutínio público etc.

AKEDIA - VERSÕES, NEGLIGÊNCIAS E OUTROS MUNDOS

V.1 DEZ. DE 2015 - ISSN 2447-7656 
são os principais atores no cenário de transformação de insegurança em segurança. E, mais que isso, também são aqueles que possuem a responsabilidade pela qualidade de vida dos cidadãos que estão sob sua circunscrição geográfica.

Nesse sentido, conforme explana Ruas (2004, p. 08), "competência gerencial é a capacidade de mobilizar, integrar e colocar em ação, conhecimentos, habilidades e formas de atuar (recursos de competência) a fim de atingir/superar desempenhos configurados na missão da empresa e da área". Desse modo, tanto no setor público quanto no privado, esse conceito se impõe como verdade.

A seu turno, as competências gerenciais de Segurança Pública, para a pesquisa em voga, carecem ser delimitadas no universo amostral das forças estaduais, devido ao grande leque de órgãos que compõem o Sistema de Segurança Pública em nosso país, conforme Artigo 144, da "Constituição Federal". Assim, temos como órgãos da Segurança Pública:

1. Polícia federal;

2. Polícia rodoviária federal

3. Polícia ferroviária federal

4. Polícias civis;

5. Polícias militares e corpos de bombeiros militares (Vide Artigo 144 da "Constituição da República Federativa do Brasil")

Nesse trabalho, então, vemos que o espaço amostral ficou delimitado pela área de atuação das forças públicas estaduais de competência das policias Civis e Militares, juntamente com o corpo de Bombeiros, tendo em vista aporte do referencial teórico do trabalho publicado pela Secretaria Nacional de Segurança Pública (SENASP), por meio de seus documentos da Matriz Curricular Nacional e estudo profissiográfico e mapeamento de competências ${ }^{10}$ dos cargos das instituições estaduais de Segurança Pública.

\footnotetext{
${ }^{10}$ É a identificação do conjunto de competências técnicas e comportamentais essenciais para o sucesso da pessoa no cargo e, consequentemente, da organização.

AKEDIA - VERSÕES, NEGLIGÊNCIAS E OUTROS MUNDOS

V.1 DEZ. DE 2015 - ISSN 2447-7656
} 


\subsection{Da qualificação às competências, uma abordagem histórica}

No final da Idade Média, o termo competência, era usado basicamente em jargões jurídicos. Significava faculdade atribuída a alguém ou a uma instituição para apreciar e julgar certas questões. Com o passar do tempo, esse conceito passou a caracterizar a capacidade de alguém pronunciar-se sobre determinado assunto (CARBONE et al, 2009).

O conceito de competência somente evoluiu para o contexto organizacional nos primórdios da Revolução Industrial. As teorias gerenciais em modelos como o do Taylorismo caracterizavam a expressão como sendo a capacidade da pessoa desempenhar eficientemente o papel na Organização (RUAS, 2004).

Assim, o modelo apresentado por Taylor (2010), voltado às empresas privadas, teve como meta a busca pela eficiência e eficácia dos resultados empresariais a partir de uma racionalização do trabalho: os métodos de produção, sob esta ótica, sempre estiveram voltados à busca do rendimento máximo em relação à produção. Essa técnica ou filosofia tem muito em comum com a definição de competências que as organizações utilizam hodiernamente.

Haja vista conferir significado próprio a partir deste modo de organizar e gerir a capacidade produtiva da empresa determinado por uma modalidade peculiar de divisão social e técnica do trabalho, o modelo de Taylor pretendia fundamentar a "parcelarização" do trabalho e a visão em busca dos melhores homens, ou seja, os "competentes" (CARBONE et al, 2009).

No contexto Taylorista, a competência assume o significado de um saber-fazer, o qual antes era derivado da experiência vivida, mas agora tem como base o conhecimento científico, nas formas do fazer (RUAS, 2004).

Conforme vemos em Lima (2006), com o declínio do sistema capitalista na década de 20 , do século $X X$, iniciou-se o momento em que o modelo taylorista de produção teve maior vigor, fato que se manteve durante quase todo o século $\mathrm{XX}$ na indústria, mas que posteriormente também entrou em declínio nesse segmento do mercado. Esse modelo, contudo, é considerado um marco na Administração Empresarial, graças ao enfoque na divisão de tarefas e no objetivo de aumento da eficiência no nível operacional. Por isso o 
taylorismo é considerado um grande clássico da Administração, tendo ainda como sustentáculo o sistema capitalista, atingindo seu ápice no início do século $\mathrm{XX}$.

Uma das condições determinantes para a derrocada deu-se a partir do fato de que não se conseguiu garantir a reprodução do capital e enfrentar as oposições dos trabalhadores quanto ao trabalho muitas das vezes extremamente repetitivo, rígido e fragmentado. Outros fatores também contribuíram para a crise do capitalismo da década de 20 , fatores que também afetaram os modelos de produção em massa (LE BOTERF, 2003).

Com este cenário, surgem novos contornos no modo de produção do sistema capitalista, também incertos nas exigências de qualificação do trabalhador, os quais passaram a ser reestabelecidos. O desenvolvimento de capacidades intelectuais que auxiliavam o trabalhador a conhecer diferentes etapas da produção, além da dimensão técnica obtida por meio de um conhecimento mais amplo acarretou, por conseguinte, um aumento no nível de escolaridade do trabalhador (LIMA, 2006).

A formação educacional naquela época passou a ter a necessidade de comtemplar não só os conhecimentos operativos, os quais eram subordinados ao "saber-fazer", mas também ao "saber-ser". As metodologias de ensino profissional adotadas pelo sistema taylorista baseavam-se na passagem de conhecimentos ordenados e sistemáticos, o que gerou questionamentos por causa da pouca correspondência com as demandas de qualificação do trabalhador (DELUIZ, 2004).

Nesse diapasão, várias responsabilidades e poderes foram demandados e canalizados em um líder, o que a administração norte-americana denominou como empowerment ${ }^{11}$. Nesse modelo, os operários eram responsáveis pela qualidade, possuíam autonomia para a correção de defeitos, dentre outros. Esses aspectos geraram um aumento significativo na qualidade e produtividade dos serviços das empresas graças a esse a maior autonomia e poder dos funcionários (DELUIZ, 2004).

\footnotetext{
${ }^{11}$ Filosofia de gestão empresarial que defende a necessidade de se dar mais autonomia responsável às pessoas que executam a tarefa, para resolução de problemas próprios de sua esfera de ação, ao contrário do que propõe a lógica taylorista e a lógica da burocracia.
}

AKEDIA - VERSÕES, NEGLIGÊNCIAS E OUTROS MUNDOS

V. 1 DEZ. DE 2015 - ISSN 2447-7656 
Este novo perfil fez com que o trabalhador fosse exigido para uma formação profissional pautada em novas visões, as quais vislumbraram a organização e a gestão do trabalho com uma derivação sociocultural mais genérica que promovesse o ensino de novas habilidades e competências, nas condições em que o mundo produtivo demanda (ZARIFIAN, 2012).

O caminho histórico acima retrata um contexto em que 0 desenvolvimento de competências por parte dos trabalhadores passou a ser mais valorizado do que a habilidade na mera execução de tarefas. Isso foi extremamente necessário para o soerguimento do sistema capitalista, que na década de vinte teve sua pior crise. Desde então, o tema das competências vem despertando interesses no meio acadêmico e na área gerencial de empresas e, desse modo, compõe o ambiente de motivações norteadoras de nossa pesquisa.

\subsection{Conceito de competência segundo a corrente francesa}

Dutra (2010) nos elenca que existem duas correntes que ajudam na conceituação da palavra competência: uma norte-americana e outra francesa. Assim, vemos que, para a corrente norte-americana, o termo competência é entendido como um conjunto de conhecimentos, habilidades e atitudes do indivíduo, que possibilita o credenciamento para a execução de determinado trabalho, de determinada função dentro da empresa. Esta corrente é defendida por autores como Boyatzis (1982) e McClelland (1973).

Já, para a corrente francesa, a competência não está relacionada a um conjunto de qualificações do indivíduo, mas àquilo que ele consegue produzir ou realizar no trabalho. Logo, para essa corrente, competência é uma resultante da combinação de múltiplos saberes: saber-fazer, saber agir, saberser, de forma a dar as respostas efetivas aos desafios atuais do mundo dos negócios. Esta corrente é defendida por autores como Le Bortef (2003), Zarifian (2012) e Perrenoud (2007).

Este trabalho coaduna mais com a corrente francesa, haja vista a intenção de mapeamento de competências estruturais gerenciais na área de Segurança Pública, de forma a se estabelecer uma sinergia entre as aptidões, 
ações e resultados que os Gestores Públicos de segurança poderão produzir, caso ocorra esse desenvolvimento de competências nas fases de capacitação ou até mesmo, no arcabouço de suas vivencias pessoais.

Atualmente, existe uma tendência conciliadora em relação ao conceito de competência. Nela, procura-se alinhar elementos das escolas francesa e americana (HELAL, et al, 2009). Carbone, et al (2009, p. 43), integrou o pensamento das duas correntes e definiu competência:

Não como o conjunto de conhecimentos, habilidades e atitudes necessários para exercer determinada atividade, mas também como o desempenho expresso pela pessoa em um dado contexto, em termos de comportamentos e realizações decorrentes da mobilização e aplicação de conhecimentos, habilidades e atitudes no trabalho.

Assim, de forma sintética, temos uma derivante conceitual do aludido tema como emerge como sendo a combinação sinérgica de conhecimentos, habilidades e atitudes, expressas pelo desempenho profissional dentro de determinado contexto organizacional. Contudo, vale dizer que isso só terá validade, desde que fortaleça não apenas as organizações, mas, também, as pessoas e, sobretudo, contribua para a construção da capacidade de realização do serviço prestado por estes integrantes (CARBONE, et al, 2009; LE BOTERF, 2003; ZARIFIAN, 2012). As competências gerenciais para os gestores de Segurança Pública devem ser desenvolvidas para o bom funcionamento do serviço público.

\subsection{O discurso sobre competências gerenciais na Administração Pública}

A administração Pública, como qualquer administração, acompanha os anseios da sociedade. As transformações sociais e culturais decorrentes do processo de uma economia globalizada reforçam o contexto político e social que tem como pilar o desenvolvimento do conhecimento, configurando-se, assim, em fator de interferência direta nas instituições, conforme (PICARELLI, 2002).

De acordo ainda com Picarelli (2002), devido às mudanças globais, as empresas passaram a buscar flexibilidade em suas operações, com o intuito de 
fortalecer sua competitividade, aumentando o gerenciamento dos riscos e as ameaças do mercado. Desse modo, o profissional que está sempre capacitado a traduzir, interpretar, decodificar cenários e demandas, de acordo com 0 aporte logístico e humano disponível, pode visar à implementação de políticas públicas com mais eficiência (DAGNITO, 2012).

A Escola da Administração Pública, para muitos, foi derivada da Escola da Administração Geral. Para aquela, a premissa de separação entre o político e o administrativo, muitas das vezes, se faz como uma dicotomia forte e latente, difícil de dissociar.

Para o poder público mineiro, um gestor público é um ocupante de cargo de direção e de chefia da alta administração, das estruturas básica e intermediária na administração direta, fundacional e autárquica do Poder Executivo do Estado de Minas Gerais, conforme estudo de perfil de Competências dos Gestores Públicos (MINAS, 2007).

Hodiernamente, temos também a expressão "a nova Gestão Pública”, sendo entendida como uma gestão envolvida com parcerias, tanto públicas quanto privadas, trazendo consigo aspectos que envolvem o Terceiro Setor ${ }^{12}$, responsabilidades sociais e empresariais (DAGNITO, 2012).

Segundo Dias (2008), "a nova Gestão Pública”, instituída na década de 90 , considera que a eficiência ${ }^{13}$ da máquina pública é buscada na competência para a obtenção de resultados para o cidadão e na qualificação do funcionalismo público. Dessa feita, os resultados positivos podem ser obtidos partindo da responsabilização de competências administrativas e pela implementação de uma gestão ${ }^{14}$ pública orientada pela assunção de resultados.

Corroborando este contexto, Guimarães (2000) explicita que 0 gerenciamento por competência é uma forma de aplicar as mudanças e as

\footnotetext{
12 O terceiro setor constitui-se na esfera de atuação pública não-estatal, formado a partir de iniciativas privadas, voluntárias, sem fins lucrativos, no sentido do bem comum. Incluem-se organizações não governamentais, fundações e institutos empresariais, associações comunitárias, entidades assistenciais e filantrópicas, assim como várias outras instituições sem fins lucrativos.

${ }^{13}$ Pode ser entendida como a capacidade de minimizar o uso de recursos para alcançar as metas definidas, ou seja, é a capacidade de otimizar o uso dos recursos, e seria medida pela relação entre recursos aplicados e o produto final obtido (LACOMBE, 2004).

${ }^{14}$ Para fins da presente pesquisa, o termo gestão é lido como sinônimo de administração e, assim, significa um conjunto de princípios, de normas e de funções que têm por fim ordenar os fatores de produção e controlar a sua produtividade e a sua eficiência, para obter determinado resultado.
}

AKEDIA - VERSÕES, NEGLIGÊNCIAS E OUTROS MUNDOS

V. 1 DEZ. DE 2015 - ISSN 2447-7656 
inovações necessárias na administração pública para otimização de seus desempenhos, contribuindo para agregação de valor à instituição. Desse modo, podemos inferir que uma gestão eficiente baseada nos principais norteadores de competências gerenciais, sem sombra de dúvida, pode estimular o alinhamento, a integração, o compartilhamento e o direcionamento ao sucesso de toda a organização, apontando, assim, para o caminho da excelência ${ }^{15}$ em sua esfera de atuação, o que pode gerar não só valor à organização, mas, também resultados em todas as partes do cenário.

$\mathrm{Na}$ dimensão de competências gerenciais macro, demonstra Boyatzis (apud LIMA, 2007), que a definição de seis categorias de competências interligadas ao "saber-ser", são importantes para a construção de um perfil com padrão de excelência para um gestor:

a) metas e gestão pela ação: orientação eficiente, produtividade, diagnóstico e uso de conceitos, preocupação com impacto (pró-atividade).

b) liderança: autoconfiança usa de apresentações orais, pensamento lógico, conceitualização.

c) recursos humanos: uso de poder socializado, otimismo, gestão de grupo, autoavaliação e senso crítico.

d) direção de subordinados: desenvolvimento de outras pessoas, uso de poder

unilateral e espontaneidade.

e) foco em outros clusters: autocontrole, objetividade perceptual, adaptabilidade, preocupação com relacionamentos próximos.

f) conhecimento especializado: memória e conhecimento especializado.

Desse modo, podemos também salientar que o governo de Minas Gerais, no ano de 2007, elaborou um estudo de perfis de competências dos gestores públicos do Poder Executivo, tendo como eixos articuladores as competências macro: Visão Sistêmica, Compartilhamento de Informações e Conhecimentos, Liderança de Equipes, Capacidade Inovadora, Gestão de Pessoas, Competência Técnica e Orientação para Resultados.

Competências essas que muito se aproximam do modelo de competência da corrente Francesa, principalmente pela preocupação quanto à mobilização de saberes, atitudes em prol dos resultados organizacionais.

\footnotetext{
15 “A excelência é um horizonte, uma busca contínua. Não há como permanecer no ponto em que pensamos tê-la alcançado." Autor Desconhecido.

AKEDIA - VERSÕES, NEGLIGÊNCIAS E OUTROS MUNDOS

V. 1 DEZ. DE 2015 - ISSN 2447-7656
} 


\subsection{Competências gerenciais, segundo Doutrina Nacional da Secretaria Nacional de Segurança Pública}

No mapa de competências dos profissionais de segurança pública elaborado pela SENASP (Secretaria Nacional de Segurança Pública), em 2003, identificaram-se três dimensões de competências: as cognitivas, as atitudinais e as operativas, as quais também estão interligadas ao "saber-ser", "saberfazer" e ao "saber".

Essas dimensões estão dispostas no seguinte sentido:

a) Saber (competências cognitivas): competências que requerem o desenvolvimento do pensamento superior reflexivo por meio da investigação e da organização do conhecimento. São os conhecimentos gerais ou especializados que deve possuir. Aprende-se através da compreensão de conteúdos.

b) Saber-fazer (competências operativas): competências que preveem a aplicação do conhecimento teórico em prática responsável, refletida e consciente. É o domínio de instrumentos e métodos cuja utilização é necessária para um bom desempenho profissional.

c) Saber-ser (competências atitudinais): competências que visam estimular a percepção da realidade, por meio do conhecimento e do desenvolvimento das potencialidades individuais. São as atitudes relacionadas a julgamentos pessoais sobre: conveniência ou não de agir, qualidade do trabalho, ética comportamental, participação, solidariedade, criatividade, iniciativa, proatividade, dentre outros atributos humanos. Enseja modificação de atitudes e a formação, normalmente, é eficaz em longo prazo (BRASIL, 2013).

De forma mais específica, tendo como base o estudo do perfil profissiográfico do Mapeamento de Competências das Forças Públicas Estaduais, elaborado pelo Departamento de Pesquisa, Análise da Informação e Desenvolvimento de Pessoal - DEPAID, da Secretária de Segurança Pública, temos como norte, o seguinte direcionamento de competências cognitivas para os gestores ${ }^{16}$ de segurança pública:

a) Capacidade de visão sistêmica (ter compreensão do todo em uma determinada situação; ser capaz de combinar partes coordenadas entre si e que formam um conjunto).

b) Capacidade de raciocínio espacial (visualizar a posição, organização e modificação de um objeto no espaço.

\footnotetext{
${ }^{16}$ Para efeito desse estudo consideram-se gerentes, gestores e diretores como sinônimos.

AKEDIA - VERSÕES, NEGLIGÊNCIAS E OUTROS MUNDOS V. 1 DEZ. DE 2015 - ISSN 2447-7656
} 
c) Capacidade de raciocínio abstrato (estabelecer relações em situações novas para as quais se possua pouco conhecimento previamente aprendido).

d) Capacidade de raciocínio numérico (compreender e manejar sistemas numéricos, realizando operações matemáticas com exatidão)

e) Capacidade de raciocínio mecânico (compreender princípios de funcionamento de mecanismos simples ou complexos e para manipular ou consertar estes mecanismos)

f) Capacidade de raciocínio lógico (saber resolver problemas com objetividade, coerência e rapidez)

g) Capacidade de raciocínio verbal (expressar-se com facilidade, ter fluência verbal e escrita)

h) Ter raciocínio dedutivo (saber raciocinar por dedução)

i) Capacidade de atenção concentrada (manter a atenção focada apenas em uma atividade, não permitindo que algo externo interfira)

j) Capacidade de atenção difusa (manter a concentração em uma dada atividade, ao mesmo tempo em que está atento ao que está acontecendo em sua volta)

k) Capacidade de memória visual, fisionômica e/ou auditiva (recordar informações, dados, fatos, conhecimentos percebidos e fisionomia de pessoas, mantendo a lembrança de qualquer coisa ou de alguém)

I) Capacidade de observação (reparar ou perceber características ou aspectos que ocorrem com as pessoas, situações, fatos, objetos ou local/ambiente)

m)Capacidade de objetividade (saber-ser direto e preciso; manter o foco na tarefa, ser conciso)

n) Capacidade de agir com rapidez de raciocínio

o) Capacidade de agir com celeridade (agir com rapidez e perspicácia)

p) Acuidade visual (boa visão, diferenciar detalhes)

q) Capacidade de análise e síntese

r) Capacidade de persuasão e argumentação (poder de convencimento, capacidade de argumentar e contra argumentar)

s) Capacidade de adaptação a imprevistos

\section{MAPEAMENTO DE COMPETÊNCIAS GERENCIAIS DE SEGURANÇA PÚBLICA}

\subsection{Competências gerenciais de Segurança Pública: uma abordagem analítica}

O mapeamento de competências delimita quais as competências técnicas (conhecimentos e habilidades) e competências comportamentais (atitudes) são necessárias ao cargo analisado para que se tenha maior eficácia para a organização, como entende Carbone (2009).

O mapeamento de competências, segundo Carbone (2009), tem como finalidade identificar lacunas entre as competências necessárias para AKEDIA - VERSÕES, NEGLIGÊNCIAS E OUTROS MUNDOS V. 1 DEZ. DE 2015 - ISSN 2447-7656 
concretizar a estratégia da organização, mescladas com as competências profissionais por meio de pessoas "chaves", como especialistas, membros de diretorias etc. Serve ainda para identificar as habilidades, conhecimentos e atitudes que dispõem os diversos profissionais, os quais as utilizam para realizar determinada tarefa.

A redução ou eliminação destas eventuais lacunas de competências está condicionada ao mapeamento das competências necessárias à consecução da estratégia organizacional, para que a instituição produza competitivamente em seu mercado.

Tendo como base o documento "Mapeamento de Competência: perfil desejado para o profissional de segurança pública", elaborado pela Polícia Militar do Estado de Minas Gerais, no ano de 2003, o qual teve como uma de suas finalidades a identificação das principais competências na área de Segurança Pública, podemos depreender o conceito de competências estruturais, as quais são atinentes ao "saber-ser" (aptidões e traços de personalidade) que são difíceis de mudar através de ações de qualificação e treinamento por se tratarem de traços da personalidade (MINAS, 2003).

Assim, o estudo mineiro mencionado acima, nos traz uma definição de Competência Estrutural que particularmente nos interesse para as reflexões aqui realizadas:

São aspectos cujo desenvolvimento depende mais da história de vida de cada um (vivência e experiência pessoal) do que propriamente do processo de ensino e aprendizagem formal. Contudo, são fundamentais para subsidiar o processo seletivo e de acompanhamento de pessoal (incluindo a avaliação de desempenho) na medida em que, uma vez existentes, favorecem o processo de formação e aperfeiçoamento.

Dessa feita, os fatores que concorrem para uma boa gestão, deixam-se notar por meio do princípio de um bom mapeamento de competências estruturais, as quais podem interligar a relação dos conhecimentos, habilidades e atitudes, juntamente com os traços de personalidade que devem ser desenvolvidos para o bom funcionamento do serviço público na área de Segurança Pública, ou seja, a identificação de competências inatas ao gerente de segurança, identificada desde o processo de seleção, aperfeiçoamento ou 
capacitação, pode auxiliar em melhores resultados organizacionais, o que, de forma direta, também beneficia o público local.

Logicamente, gestão pela ação, liderança, gestão de recursos humanos, foco em outros clusters e conhecimento especializado são competências macro de quaisquer cargos gerenciais. Todavia, são competências sine qua non ${ }^{17}$ para os cargos gerenciais de segurança pública, de forma que esses profissionais as adquiram e as executem de perenemente.

As qualidades ou habilidades elencadas para os gestores de Segurança Pública, do mapeamento da Secretaria Nacional de Segurança Pública, se não forem colocadas à disposição dos propósitos institucionais, não gerarão resultados e, desse modo, em apartado, esses conhecimentos, habilidades e atitudes não estarão em sinergia, de forma que não serão competências por não gerarem resultados.

As capacidades de visão sistêmica, raciocínio espacial, raciocínio abstrato, raciocínio numérico, raciocínio mecânico, raciocínio lógico, raciocínio verbal, raciocínio dedutivo, atenção concentrada, atenção difusa, memória visual, fisionômica e/ou auditiva, observação, objetividade, agir com rapidez de raciocínio, agir com celeridade, acuidade visual, capacidade de análise e síntese, capacidade de persuasão/ argumentação e capacidade de adaptação a imprevistos, são competências primordiais e específicas aos cargos de gestão de Segurança Pública, segundo a Doutrina da Secretária Nacional de Segurança Pública.

Essas competências podem e devem ser estimuladas, através dos processos e procedimentos já preestabelecidos na gestão de pessoas e projetos, e também instituído na filosofia institucional ou na identidade organizacional.

Podemos inferir, que apesar de serem mais delineadas para os gestores da área de Segurança Pública, não deixam de derivar de grandes eixos articuladores de perfis de competências dos gestores públicos, como ocorre no Poder Executivo do Estado de Minas Gerais.

\footnotetext{
${ }^{17}$ Expressão latina que pode ser traduzida como "sem ao qual não pode ser"

AKEDIA - VERSÕES, NEGLIGÊNCIAS E OUTROS MUNDOS

V. 1 DEZ. DE 2015 - ISSN 2447-7656
} 


\section{CONCLUSÃO}

Evidentemente, este trabalho não teve a finalidade de esgotar o tema, pois o mesmo é complexo. Entretanto, possibilitou levantar informações que podem apoiar a implantação ou aperfeiçoamento de algumas competências gerenciais dos profissionais de Segurança Pública.

As competências individuais dos gestores de Segurança Pública também se permeiam na mesma direção dos objetivos estratégicos de suas organizações, auxiliando na efetivação dos resultados a serem alcançados.

Os principais conhecimentos, habilidades e atitudes que podem gerar resultados, através dos gestores de Segurança Pública, são excelentes ferramentas ao redirecionamento dos recursos humanos e logísticos, os quais serão capazes de influenciar pessoas ao caminho do sucesso da organização.

O trabalho em tela buscou demonstrar um mapeamento profissional dessas pessoas, a partir das principais características, perfis, compromissos e resultados almejados, inatas dos órgãos de Segurança Pública.

Dessa feita, esse esboço das principais competências dos profissionais gerenciais de Segurança Pública foi exposta, de modo sugerir que nestas características existem espaços para melhorar as lacunas existentes quanto às competências necessárias à consecução dos objetivos estratégicos das organizações de Segurança Pública em nossos ambientes sociais.

Essa análise, por sua vez, pode subsidiar as decisões e investimentos na captação e desenvolvimento de profissionais que ainda carecem de competências específicas de determinados cargos ou ainda, ajudar no processo de formação daqueles que ainda precisam apresentá-las. Com esse intuito, acreditamos que podemos tornar o nosso ambiente cada vez mais seguro, partindo de ações mais especializadas, competentes e profissionais.

Evidentemente, conforme demonstrado, mesmo os estudos científicos mais precisos, vindouros da Secretária Nacional de Segurança Pública, ainda não possuímos como precisão, um mapeamento de competências gerenciais para os gestores de Segurança Pública. O que de certa forma não está errado, uma vez que podemos concluir que ainda muito precisa ser feito, para que se alcance a excelência. 
Por fim, procuramos trazer à tona para o conhecimento dos gestores de Segurança Pública, um pequeno delineamento sobre competência, além de despertar e instigar o hábito de capacitação contínua por parte desses profissionais. Neste sentido, após a análise do conteúdo, é possível inferir que os estores de Segurança Pública possuem grande parte das competências aqui elencadas, necessitando apenas, em alguns casos, aperfeiçoá-las.

\section{REFERÊNCIAS}

ARAÚJO, Ronaldo Marcos de Lima. Desenvolvimento de competências profissionais: as incoerências de um discurso. (Tese de Doutorado). Belo Horizonte: FAE/UFMG, 2001.

BOYATZIS, R. E. The competent manager: A model for effective performance. New York: John Wiley \& Sons, 1982.

BRASIL. Secretaria Nacional de Segurança Pública/Senasp Ministério da Justiça Secretaria Nacional de Segurança Pública/Senasp. Matriz curricular nacional para a formação em segurança pública. Departamento de Pesquisa, Análise da Informação e Desenvolvimento de Pessoal em Segurança Pública. Coordenação-geral de ensino. Brasília: SENASP. 2003.

BRASIL. Secretaria Nacional de Segurança Pública. Perfil dos cargos das instituições estaduais de segurança pública: estudo profissiográfico e mapeamento de competências / Secretaria Nacional de Segurança Pública - Programa Nacional de Desenvolvimento para as Nações Unidas (PNUD) - Brasília: Ministério da Justiça, Secretaria Nacional de Segurança Pública, 2012.

CARBONE, Pedro Paulo et al. Gestão por Competências e Gestão do Conhecimento. $3^{a}$ ed. Rio de Janeiro. Ed. FGV, 2009.

CORDEIRO, B. M. P.; MUNIZ, Jacqueline de Oliveira. Mapeando competências rumo à aprendizagem continuada em segurança pública. Artigo Científico, Brasília, 2010.

DAGNINO, Renato Peixoto. Planejamento estratégico. Florianópolis: Departamento de Ciências da Administração / UFSC, 2012.

DELUIZ, Neize. O Modelo das Competências profissionais no Mundo do trabalho e na Educação: implicações para o currículo. Boletim técnico do SENAC. V. 27, n. 15-25, p.1, Set./dez.2001.

DIAS, Marcos Antônio. Desafios para a implementação de uma plataforma de gerenciamento de projetos: O caso da Policia Militar de Minas Gerais. 2008. 208 f. Monografia (Curso de Especialização em Segurança Pública). Academia de Polícia Militar de Minas Gerais e Fundação João Pinheiro, Belo Horizonte. 2008.

DUTRA, Joel Souza. Gestão por Competência. São Paulo: Gente, 2001

FLEURY, Afonso. FLEURY, Maria Tereza Leme. Construindo o conceito de competências. Revista de Administração Contemporânea (RAC), v. 5, p.183-196, 2001.

GUIMARÃES, Tomás de Aquino. A Nova Administração Pública e a abordagem da Competência. Anais do 24ํㅡㄹ Encontro da ANPAD. Florianópolis, set. 2000. 
LIMA, Hellen Soares. A administração no sistema prisional: um estudo das competências gerenciais. Belo Horizonte: FUMEC / Faculdade de Ciências Empresariais, 2007.

$2002 b$

Polícia Militar. Mapeamento de competências. Academia de Polícia Militar,

LE BOTERF, Guy. Desenvolvendo a competência dos Profissionais. Porto Alegre: Artmed, 2003.

MCCLELLAND, D. C. (1973). Testing for Competence Rather Than for "Intelligence".

American Psychologist, 28(1), 1-14.

MINAS GERAIS. Polícia Militar. Academia de Polícia Militar. Centro de Ensino Técnico. Mapeamento de competências: perfil desejado para o profissional de segurança pública. Belo Horizonte, 2003.

MINAS GERAIS. Secretaria de Estado de Planejamento e Gestão. Superintendência Central de Política de Recursos Humanos. Projeto Estruturador: Ampliação da Profissionalização dos Gestores Públicos. Belo Horizonte, 2007.

PERRENOUD, Philipe. Construir as competências desde a escola. Porto Alegre, Artes Médicas, 2000.

PICARELLI, Vicente. Gestão por competências. Manual de Gestão de Pessoas e Equipes: estratégias e tendências. São Paulo: Editora Gente, 2002.

PIRES, Alexandre Kalil et al. Gestão por Competências em Organizações do Governo. Brasília: ENAP, 2005.

RUAS, Roberto. Desenvolvimento de competências gerenciais e contribuição da aprendizagem organizacional. In: FLEURY, Maria Tereza Leme; OLIVEIRA, Moacir de Miranda Jr (orgs.). Gestão estratégica do conhecimento: integrando aprendizagem, conhecimento e competências. São Paulo: Atlas, 2004. p. 8.

TAYLOR, Frederick Winslow. Principios de Administracao Cientifica. São Paulo: Atlas, 2010.

ZARIFIAN, P. Objetivo Competência. São Paulo: Atlas, 2001.

- A Gestão pela Competência. Centro Internacional para a Educação, Trabalho e Transferência de Tecnologia. Rio de Janeiro, 1996.

$2002 b$

Polícia Militar. Mapeamento de competências. Academia de Polícia Militar,

A Gestão pela Competência. Centro Internacional para a Educação, Trabalho e Transferência de Tecnologia. Rio de Janeiro, 1996. 